
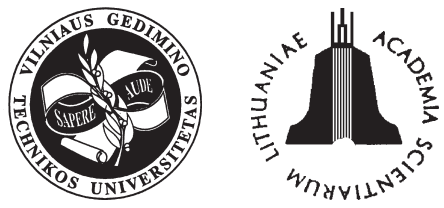

ISSN 1648-4142 TRANSPORT

www.transport.vtu.lt

\title{
RESEARCH INTO FREIGHT TRANSPORT QUEUING AT CUSTOMS CONTROL POSTS
}

\author{
Aldona Jarašūnienė \\ Vilnius Gediminas Technical University, Transport Research Institute, \\ Plytines g. 27, LT-10105 Vilnius, Lithuania \\ E-mail: ajarasuniene@yahoo.com \\ Received 2005-02-01; accepted 2005-05-25
}

\begin{abstract}
The changes after Lithuania joined the EU and customs union are analyzed here. For the transport flows forecast and the analysis of traffic at the border theories of multidimensional regression, correlation analysis and wholesale service flows are applied here, the statistical data is processed. According to these mathematical theories and methods a transport flow which will cross the outer border of the EU is forecasted. The method how to predict the amount of transport at a certain border is shown here. The research is performed to find out which custom links have problems. Conclusions and few suggestions how to quicken road traffic flows through Lithuanian customs are also presented in this work.
\end{abstract}

Keywords: road traffic flows, the theories of multidimensional regression, correlation analysis, wholesale service flows, forecast.

\section{Introduction}

New manufacturing and transport technologies request goods to be delivered to a receiver exactly, when it is necessary, so customs procedures have to be performed as fast as possible without disturbing flush movement of goods, but also not declining the effectiveness of customs control. The main object of customs is its effective work which composes reservation for businessmen and passengers to go undisturbed and freight cargo through the states border, to vouch set tax tollage, to intercept the way for smuggling and other breaches. However, today its work can be more effective and it needs sciential motivated solutions [1-3].

To evaluate significant influence of a transport sector for state economic process, to expand international transport movement it is important to improve customs work which will give economic effect, will help to store country budget, will reduce downtime in the internal and frontier customs stations made up supplementary workplaces for drivers and will help to solve human employment and other social problems. Although we improve customs work, sustaining statistics, we see that queues in our main roads stations don't go off. These reasons show the topicality of this article.
In this article the flood of transport which crosses external EU borders is analyzed. Actual conditions of Lithuanian customs and noticed changes after entering the EU and connection with Customs Union are reviewed and evaluated. The problems with regressive and correlative methods of analysis applicable in transport flood prediction are presented. Also mass service theories fitting for prospecting vehicle queues in Lithuanian customs are presented.

In general the goal of customs research is to analyze the work of its system, changes in it and to formulate scientific motivated instruments which can help to correct the whole system so that it will satisfy the changing situation.

Complex customs system research is very actual for Lithuania because after the regeneration of independence in our country the whole fundamental economic reconstruction is processing and Lithuania during a short period has to formulate not only general country transit policy, but also to be ready for the reconstruction of separate border traverse terminals and development programs. Preparing these programs we can't always quote the results of the sciential research merely because some problems have arisen anew (for example to formulate Lithuanian transport policy integration to the EU transport service market 
conditions). Some of them we only begin to solve on an international scale (for example multimodal expansion of transport technologies). Therefore it is very important to activate sciential research into these directions in the country either to integrate Lithuanian scientists to the international labour cooperation in the direction of customs and transport research.

Shortly to pass in review the Lithuanian transport situation, we can see that the main role here is played by the tendency which says that cargo volume on the international scale is increasing. Using regressive and correlative analysis methods we will try to prove that the amount of vehicles on roads crossing the external border of the EU will increase in the future. It can be the reason of increasing queues formation near the external EU border. Now the largest and the most modern customs terminals are at the border with Belarus-Medininkai and at the border with Russia-Kybartai. Statistics shows that the biggest transport queues formation is at Kybartai and Medininkai customs terminals.

Using regressive and correlative analysis methods the prognosis about transport floods crossing the external EU border are proposed. Transport queues formatted at the biggest Russia and Belarus frontiers customs terminals in Kybartai and Medininkai are researched using mass service theory.

The detalyzed and solved problems of transport flood through Lithuanian customs are evaluated.

\section{Multidimensional regression and correlation analysis using the method of transport activity prog- nosis}

In the national transport development program two of seventeen conditional independent parts are:

1. Actual transport sector characteristics and further development prognosis.

2. Roads, railway, water and air transport infrastructure development (during the integration in the EU transport network [4-6].

The prediction about transport activity is one of few stages, a complex task in the National Lithuanian transport development program. It is one of the most difficult tasks and at the same time at least analyzed in the republic and foreign literature. If there is enough literature about transport action planning problems, there is only little about prognosis. So we should pay attention to the most important tasks of transport development which is the prognosis of transport development and its reliability.

In the main case the task about prognosis can be formulated like this: let $Y=\left\{y\left(t_{i}\right)\right\}$ in one measure statistical observation line row $t_{i+1}-t_{i}=$ const at the moments where $i=1, \ldots, n$. We have to find some meanings of $T$ for some period in the future, it means at time moments $t_{j}$, where $j=n+1, \ldots, n+T$. Besides we allow exploratory inertia of a process to be like a general tendency sustention in the process of time.

A row of the time at time moment $t$ could be calculated as the sum of two components:

$$
y=f(\Theta, t)+\varepsilon(t),
$$

here $f(\Theta, t)$ - constant function of time (trend); $\varepsilon(t)$ - function with appreciative scholastic action of the factors; $\theta$ - parameter vector, which must be evaluated.

From formula $f(\Theta, t)$ characterizes the main pending process tendencies and evaluates the main action of the factors in this process. Consequently if it were successful to find $f(\Theta, t)$ - a constant part of the process, then $\varepsilon(t)$ residual part would be purely casual and it would be proved that such process is stationary.

On purpose to determine $f(\Theta, t)$ the methods of regressive and correlative analysis are applied.

Usually a researcher observes certain expression which quantifiably characterizes $y$ value which order of fall determines many actions also quantifiably evaluated by values $x, z, \ldots, t$. These can be fixed (for example certain statistical data) or such which value during research can be purposely changed by a researcher to provoke changes of researched value $y$.

Suppose that concrete complex of values $\left(x_{1}, z_{1}\right.$, $\left.\ldots, t_{1}\right)$ of variables $x, z, \ldots, t$ corresponds concrete value $y_{1}$ of researched value $y$, other complex $\left(x_{1}\right.$, $\left.z_{1}, \ldots, t_{2}\right)$ corresponds value $y_{2}$ and so on. Consequently there is a connection between variables $x$, $z, \ldots, t$ and researched value $y$. This connection can be functional or corelational $[7,8]$.

Methods of co relational analysis allow to evaluate corelational connection between variables $x, z$, ..., $t$ and the degree of dependence of researched value $y$. Using corelational connections, linear and nonlinear methods of corelational analysis, we can detect which factors characterized by values $x, z, \ldots$, $t$ are fundamental, which have small influence on value $y$, and which are not related at all. Strong corelational connections admit to presume that there are neither co-relational connections, nor functional ones. The methods of regressive analysis allow discovering attribution of last-mentioned. Getting analytical expression of the connection of the whole complex $(x, z, \ldots, t)$ and researched value $y$ with these methods, we can extrapolate that is detect values of $y$ with such $x, z, \ldots, t$ values of variables which are out of the used interval limits of values during the experiment (statistic) time. Extrapolation is the base of the prognostication of the researched expression in various situations. 
The expression of functional connection is searched with the methods of regressive analysis only when there is a possibility to foresee a function type. When it is imposible to do this, this reliance is modelled bearing to the simplicity the principle of a mathematical model. Methods of mathematic modelling, approximate approximation polynomials of functional reliance, stochastic modelling flow from this type of propositions.

Two-dimensional regression and correlative analysis are not enough for the formation of prognosis. It is needed to relate the indexes of transport proceeding with common republic economy and transport indexes, tendencies, evaluating general determinant factors and their influence on proceeding results of separate transport types. Indexes of general republic economy proceeding can be a general domestic product, national revenue, production output and so on. To find regression equation relative to prognosticate economical indexes of transportation activity (volume of cargos and passengers, turnover of cargos and passengers and so on; the whole transportation system and separate its transportation type) it is essential to use the analysis methods of multidimensional regression and correlation. In chapter 3.2 the analysis of multidimensional regression and correlation is applied to prognosticate the stream of transport and to perform the prognosis.

\section{Application of the mass attendance service theory for the estimation of queuing at the border-crossing posts}

Ideas and methods of the mass attendance service theory (MAS) are applied in the road transport for the research of technological processes, planning and transport organisation.

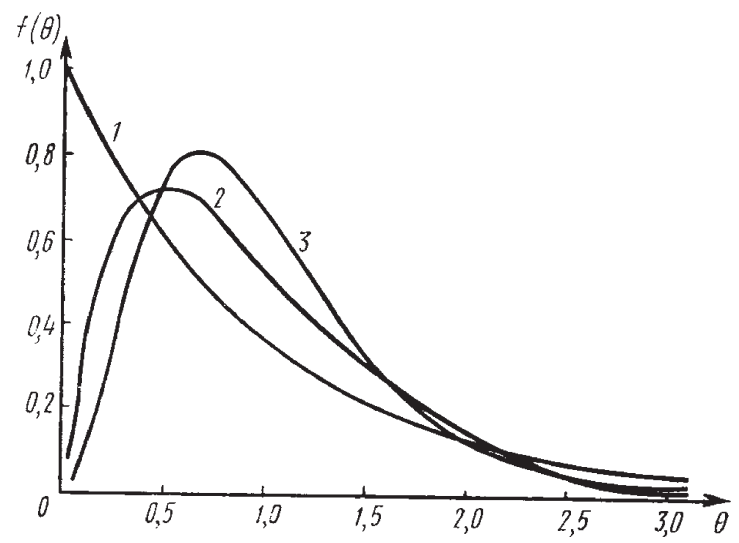

The application of the mass attendance service theory enables the solution of such tasks as: defining the number of road vehicle technical service and repair posts, calculating the quantity of loading (stuffing/stripping) centres, determining rational amounts of aggregates. On the whole, the theory enables the solution of problems dealing with the coordination of supply and demand. In terms of market economy it is a very important objective.

Contrary to the mathematical programming, the main aim of which is to find the maximum or the minimum of the objective function within certain limitations the main task of the mass attendance service theory is the formalisation of a process. The theory allows expressing the process by formulae and enables clearer definition and explanation of the situation of mass servicing and facilitates decision-making. Actually, by the application of the theory of mass attendance service and basing on obtained characteristics it is also possible to find the optimum of the object function, however, not by means of mass attendance service system.

The notion 'attendance service' implies the meaning of satisfying demands and the notion 'mass' indicates that the theory is regarding not a concrete, specific subject, but the entirety of subjects having common demand for the attendance service.

Particularity of the mass attendance service theory consists of the fact that any mass attendance service process is analysed by it as a stochastic process, thus the mass attendance service theory is a component chapter of the theory of chances having grown into an independent chapter of mathematics.

The laws of distribution applied in the theory of mass attendance service for describing the service time, are presented in the table below, and their graphic expression is presented in Fig and in table of

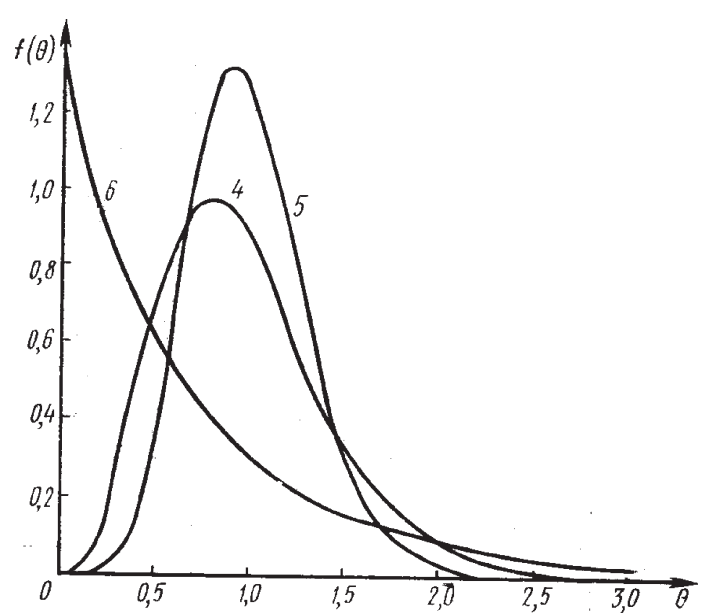

Distribution laws: 1 - exponential law (by Erlang law of distribution of the 1 st sequence); 2 - Erlang law of distribution of the 2 nd sequence; 3 - Erlang law of distribution of the 3 rd sequence; 4 - Erlang law of distribution of the 4 th sequence; 5 - Erlang law of distribution of the 10 th sequence; 6 - hyperexponential law $(\varphi=0,2)$ 
distribution laws (Table 1). In Chapter 4 the multidimensional regression and correlation analysis is applied for the research into queuing at border-crossing posts and the formalisation of queuing is performed.

\section{Research into the flows of road vehicles crossing the borders of the Republic of Lithuania}

4.1. Application of multidimensional regression and co relation analysis in forecasting of transport activities

In the simplest case assuming that there is a connection between three variables $t$ and $x$ (for example, $t$-period of time, $y$-number of vehicles) and if the connection is linear, then:

$$
y^{\prime}=a t+b .
$$

If the connection is not linear, but that of the second degree, then:

$$
y^{\prime \prime}=a t^{2}+b t+c .
$$

The following task arises: to calculate the parameters $a, b$ of regression equations (1) or parameters $a, b, c$ (2).

This task is solved by the method of least quadrates, the essence of which lies in finding such param-

\begin{tabular}{|c|c|c|c|c|c|c|}
\hline $\begin{array}{c}\text { Name of } \\
\text { law }\end{array}$ & Integrated distribution law & Relative density & \begin{tabular}{|c|} 
Mathe- \\
matical \\
preci- \\
sion \\
\end{tabular} & Dispersion & $\begin{array}{l}\text { Variation } \\
\text { coefficient }\end{array}$ & Moda \\
\hline $\begin{array}{c}\text { Expo- } \\
\text { nential }\end{array}$ & $F(\theta)=\left\{\begin{array}{l}0, \text { given } \theta<0 \\
1-e^{\lambda \theta}, \text { given } \theta \geq 0\end{array}\right.$ & $f(\theta)=\lambda e^{-\lambda \theta}$ & $M[\theta]=$ & $D[\theta]=\frac{1}{\lambda^{2}}$ & 1 & 0 \\
\hline \begin{tabular}{|c|} 
Expo- \\
nential \\
by 2 \\
parame- \\
ters \\
\end{tabular} & $F(\theta)=\left\{\begin{aligned} 0, & \text { given } \theta<a, \\
1-e^{-\lambda(\theta-a)}, & \text { given } \theta \geq a \\
& \text { and } a>0\end{aligned}\right.$ & $f(\theta)=\lambda e^{k-\lambda(\theta-a)}$ & $a+\frac{1}{\lambda}$ & $\frac{1}{\lambda^{2}}$ & $\frac{1}{a \lambda+1}$ & $a$ \\
\hline \begin{tabular}{c|} 
by \\
Erlang
\end{tabular} & $\begin{array}{c}F_{k}(\theta)=1-e^{-\lambda_{k} \theta} \\
\sum_{n-1}^{k-1} \frac{\left(\lambda_{k} \theta\right)^{n}}{n !} \\
k-\text { integer number }\end{array}$ & $f_{k}(\theta)=\frac{\lambda_{k}^{k} \theta^{k-1} e^{-\lambda_{k} \theta}}{(k-1) !}$ & $\frac{1}{\lambda}$ & $\frac{1}{k \lambda^{2}}$ & $\frac{1}{\sqrt{k}}$ & $\begin{array}{l}M[\theta] \times \\
\frac{k-1}{k}= \\
\frac{k-1}{\lambda k}\end{array}$ \\
\hline $\begin{array}{l}\text { Hiper- } \\
\text { expo- } \\
\text { nential }\end{array}$ & $\begin{array}{c}F(\theta)=1-\left[\underline{e} e^{-2 \varphi \lambda \theta}+(1-\varphi) e^{-2(1-\varphi) \lambda \theta}\right] \\
\text { and } 0<\varphi \leq 0,5\end{array}$ & $\begin{array}{l}f(\theta)=2 \varphi^{2} \lambda e^{-2 \varphi \lambda \theta}+ \\
2(1-\varphi)^{2} \lambda e^{-2(1-\varphi) \lambda \theta}\end{array}$ & $\frac{1}{\lambda}$ & $\frac{1-2 \varphi(1-\varphi)}{2 \lambda^{2} \varphi(1-\varphi)}$ & $\sqrt{1+\frac{(1-2 \varphi)^{2}}{2 \varphi(1-\varphi)}}$ & 0 \\
\hline Normal & $F(\theta) \int_{-\infty}^{\theta} \frac{1}{\sigma \sqrt{2 \pi}} \times e^{-\frac{1}{2} \cdot \frac{(t-M[\theta])^{2}}{\sigma^{2}}} \times d t$ & $\begin{array}{l}f(\theta)=\frac{1}{\sigma \sqrt{2 \pi}} \times \\
e^{-\frac{1}{2} \cdot \frac{(t-M[\theta])^{2}}{\sigma^{2}}}\end{array}$ & $M[\theta]$ & $\sigma^{2}$ & $\frac{\sigma}{\mathrm{M}[\theta]}$ & $M[\theta]$ \\
\hline
\end{tabular}

Table 1. Distribution laws eters of regression equations that the analytical values of $y_{i}$ should minimally deviate from the actual statistical data values $y_{i}^{*}$ i.e.:

$$
S=\sum_{i=1}^{n}\left(y_{i}-y_{i}^{*}\right)^{2} \rightarrow \min .
$$

It if putting $y_{i}(1)$ or (2), will by:

$$
S_{1}=\sum_{i=1}^{n}\left(a t_{i}+b-y_{i}^{*}\right)^{2} \rightarrow \min
$$

or

$$
S_{2}=\sum_{i=1}^{n}\left(a t_{i}^{2}+b t_{i}+c-y_{i}^{*}\right)^{2} \rightarrow \min .
$$

While differentiating $S_{1}$, according to $a, b$ or $S_{2}$ according to $a, b, c$ and equating to zero the derivatives for parts (finding extreme points) we will obtain the system of equations (3) when the connection is linear and (4), when the connection is non-linear from the first correlation table (Table 2) [9-12].

$$
\left\{\begin{array}{l}
a \sum_{i=1}^{n} t_{i}^{2}+b \sum_{i=1}^{n} x_{i}=\sum_{i=1}^{n} y_{i} t_{i} \\
a \sum_{i=1}^{n} t_{i}+b n=\sum_{i=1}^{n} y_{i} .
\end{array}\right.
$$




$$
\left\{\begin{aligned}
a \sum_{i=1}^{n} t_{i}^{4}+b \sum_{i=1}^{n} t_{i}^{3}+c \sum_{i=1}^{n} t_{i}^{2} & =\sum_{i=1}^{n} y_{i} t_{i}^{2} \\
a \sum_{i=1}^{n} t_{i}^{3}+b \sum_{i=1}^{n} t_{i}^{2}+c \sum_{i=1}^{n} t_{i} & =\sum_{i=1}^{n} y_{i} t_{i} \\
a \sum_{i=1}^{n} t_{i}^{2}+b \sum_{i=1}^{n} t_{i}+c \cdot n & =\sum_{i=1}^{n} y_{i}
\end{aligned}\right.
$$

Table 2. First correlation table

\begin{tabular}{|l|l|l|l|l|}
\hline$t$ & $t_{1}$ & $t_{2}$ & $\ldots$ & $t_{n}$ \\
\hline$y$ & $y_{1}$ & $y_{2}$ & $\ldots$ & $y_{n}$ \\
\hline
\end{tabular}

After solving the system of equations (3), we will calculate (1) equation coefficients $a, b$, and after solving the (4) equation system we shall find (2) equation coefficients $a, b, c$. Basing on the obtained equations (1) or (2) with certain probability it is possible to forecast what values of the function will correspond to such values of variables that are beyond the statistical data, i.e. several future calendar periods ahead. In our case we show two analytical expressions (1) and (2) of functions $f(t)$ of different character. We supplement the statistical data (the correlation table 3 ) by calculating respective values of $y_{i}^{\prime}$, and $y_{i}^{\prime \prime}$ :

Table 3. Second correlation table

\begin{tabular}{|c|c|c|c|c|}
\hline$t$ & $t_{1}$ & $t_{2}$ & $\ldots$ & $t_{n}$ \\
\hline$y$ & $y_{1}$ & $y_{2}$ & $\ldots$ & $y_{n}$ \\
\hline$y^{\prime}$ & $y_{1}^{\prime}$ & $y_{2}^{\prime}$ & $\ldots$ & $y_{n}^{\prime}$ \\
\hline$y^{\prime \prime}$ & $y_{1}^{\prime \prime}$ & $y_{2}^{\prime \prime}$ & $\ldots$ & $y_{n}^{\prime \prime}$ \\
\hline$\left(y-y^{\prime}\right)^{2}$ & $\left(y_{1}-y_{1}^{\prime}\right)^{2}$ & $\left(y_{2}-y_{2}^{\prime}\right)^{2}$ & $\ldots$ & $\left(y_{n}-y_{n}^{\prime}\right)^{2}$ \\
\hline$\left(y-y^{\prime \prime}\right)^{2}$ & $\left(y_{1}-y_{1}^{\prime \prime}\right)^{2}$ & $\left(y_{2}-y_{2}^{\prime \prime}\right)^{2}$ & $\ldots$ & $\left(y_{n}-y_{n}^{\prime \prime}\right)^{2}$ \\
\hline
\end{tabular}

Calculating sum total:

$$
S_{1}=\sum_{i=1}^{n}\left(y_{i}-y_{i}^{\prime}\right)^{2} \text { and } S_{2}=\sum_{i=1}^{n}\left(y_{i}-y_{i}^{\prime \prime}\right)^{2}
$$

If $S_{1}<S_{2}$ then more precise is $y^{\prime}=a t+b$ analytical expression, if $S_{2}<S_{1}$, then more precise is the $y^{\prime \prime}=a t^{2}+b t+c$ expression.

Calculations have been carried out by applying the Microsoft Excel and R 1.8.1 programmes.

4.2. Forecast of quantity of road vehicles having left Lithuania through the Byelorussian border

In Table 4 there are statistical data on the quantities of road freight vehicles that left Lithuania through the Byelorussian border in the period from 2001 to 2004. By applying the methods of regressive and correlation analysis used for forecasting of transport activities, we find the dependence/subjection $y=f(x)$. This dependence can be linear and non-linear.

Linear dependence: $y=a x+b$.

Non-linear dependence: $y^{\prime \prime}=a x^{2}+b x+c$.

Having performed the calculations we obtain the equation of linear dependence:

$$
y=583,36 x+25337,13 .
$$

Non-linear dependence equation:.

$$
y^{\prime \prime}=4,83 x^{2}+578,53 x+25235,70 \text {. }
$$
Table 5.

Calculated values of $y$ and $y^{\prime \prime}$ are presented in

Having performed the calculations we see that in this case for the forecasting the equation of nonlinear dependence is more suitable. According to fore-

\begin{tabular}{|c|c|c|c|c|c|c|c|c|c|c|c|c|c|}
\hline Years & & & & & 2002 & & & & \begin{tabular}{|l}
2003 \\
\end{tabular} & & & & 2004 \\
\hline Quarters & 1 & 2 & 3 & 4 & 1 & 2 & 3 & 4 & 1 & 2 & 3 & 4 & $1-4$ \\
\hline Leaving quantities & 22713 & 26504 & 24135 & 28477 & 27805 & 24371 & 23035 & 26980 & 25420 & 29627 & 27108 & 34862 & 30259 \\
\hline
\end{tabular}
casts for the year 2005 presented in Table 5, we see that the quantities of freight road vehicles leaving Lithuania through the Byelorussian border show the

\begin{tabular}{|c|c|c|c|c|c|c|c|c|c|c|c|c|c|c|}
\hline Years & \multicolumn{4}{|c|}{2001} & \multicolumn{4}{|c|}{2002} & \multicolumn{4}{|c|}{2003} & 2004 & 2005 \\
\hline Quarters & 1 & 2 & 3 & 4 & 1 & 2 & 3 & 4 & 1 & 2 & 3 & 4 & $1-4$ & $1-4$ \\
\hline Leaving quantities & 22713 & 26504 & 24135 & 28477 & 27805 & 24371 & 23035 & 26980 & 25420 & 29627 & 27108 & 34862 & 120941 & $\begin{array}{c}\text { Fore- } \\
\text { cast }\end{array}$ \\
\hline linear dependence, $y$ & 23587 & 24170 & 24754 & 25337 & 25920 & 26504 & 27087 & 27671 & 28254 & 28837 & 29421 & 30004 & & \\
\hline non-linear dependence, $y^{\prime \prime}$ & 23544 & 24098 & 24662 & 25236 & 25819 & 26412 & 27015 & 27627 & 28249 & 28881 & 29522 & 30173 & 129900 & 135534 \\
\hline
\end{tabular}
tendency of growth.

Table 4. Quantities of freight road vehicles leaving Lithuania through the Byelorussian border

Table 5. Quantities of freight road vehicles leaving Lithuania through the Byelorussian border show the tendency of growth 


\subsection{Forecast of quantity of road vehicles com- ing to Lithuania through the Byelorussian border}

Table 6 presents statistical data on the quantities of freight road vehicles coming to Lithuania through the Byelorussian border in the period from 2001 to 2004. Having applied the methods of the regressive and correlation analysis used for forecasting of transport activities, we find the dependence $y=f(x)$. This dependence can be linear and non-linear.

Linear dependence: $y=a x+b$.

Non-linear dependence: $y^{\prime \prime}=a x^{2}+b x+c$.

Having performed the calculations we obtain the equation of the linear dependence:

$$
y=541,29 x+24095,23
$$

The equation of non-linear dependence:

$$
y^{\prime \prime}=40,15 x^{2}+501,13 x+23251,98 \text {. }
$$

6.

Calculated values of $y$ and $y^{\prime \prime}$ are given in Table

Having performed the calculations we see that non-linear dependence equation is more suitable for forecasting in this case. According to forecasting for the year 2005 presented in Table 7 we see that the quantities of freight road vehicles coming to Lithuania through the Byelorussian border will grow.

\subsection{Forecast of quantity of road vehicles leav-} ing Lithuania through the Russian border

Table 8 presents statistical data on quantities of road freight vehicles that left Lithuania through the Russian border within the period from 2001 to 2004. By applying the methods of regressive and correlation analysis used for forecasting of transport activities, we find the dependence $y=f(x)$. This dependence can be linear and non-linear.

Linear dependence: $y=a x+b$.

Non-linear dependence: $y^{\prime \prime}=a x^{2}+b x+c$.

Having performed the calculations we obtain the equation of linear dependence:

$$
y=169,22 x+13929,64 .
$$

Non-linear dependence equation:

$$
y^{\prime \prime}=12,93 x^{2}+156,29 x+13658,16 \text {. }
$$

Calculated values of $y$ and $y^{\prime \prime}$ are presented in Table 9. Having performed the calculations we see that non-linear dependence equation is more suitable for forecasting in this case. According to forecasts for the I quarter of the year 2005 presented in Table 9 we see that the quantities of freight road ve-

\begin{tabular}{|c|c|c|c|c|c|c|c|c|c|c|c|c|c|}
\hline Years & \multicolumn{4}{|c|}{2001} & \multicolumn{4}{|c|}{2002} & \multicolumn{4}{|c|}{2003} & 2004 \\
\hline Quarters & 1 & 2 & 3 & $\overline{4}$ & 1 & 2 & 3 & 4 & 1 & 2 & 3 & 4 & $\overline{1-4}$ \\
\hline Coming quantities & 19868 & 24276 & 22569 & 25594 & 24179 & 24246 & 22920 & 26282 & 21814 & 27876 & 26548 & 34806 & 130994 \\
\hline
\end{tabular}
hicles leaving Lithuania through the Russian border will grow.

Table 6. Quantities of freight road vehicles coming to Lithuania through the Byelorussian border

\begin{tabular}{|c|c|c|c|c|c|c|c|c|c|c|c|c|c|c|}
\hline Years & \multicolumn{4}{|c|}{2001} & \multicolumn{4}{|c|}{2002} & \multicolumn{4}{|c|}{2003} & 2004 & 2005 \\
\hline Quarters & 1 & 2 & 3 & 4 & 1 & 2 & 3 & 4 & 1 & 2 & 3 & 4 & $1-4$ & $1-4$ \\
\hline Coming quantities & 19868 & 24276 & 22569 & 25594 & 24179 & 24246 & 22920 & 26282 & 21814 & 27876 & 26548 & 34806 & 130994 & $\begin{array}{c}\text { Fore- } \\
\text { cast }\end{array}$ \\
\hline linear dependence, $y$ & 22471 & 23013 & 23554 & 24095 & 24637 & 25178 & 25719 & 26260 & 26802 & 27343 & 27884 & 28426 & & \\
\hline non-linear dependence, $y^{\prime \prime}$ & 22110 & 22410 & 22791 & 23252 & 23793 & 24415 & 25117 & 25899 & 26762 & 27704 & 28727 & 29831 & 134010 & 135041 \\
\hline
\end{tabular}

Table 7. Quantities of freight road vehicles coming to Lithuania through the Byelorussian border show the tendency of

\begin{tabular}{|c|c|c|c|c|c|c|c|c|c|c|c|c|c|}
\hline Years & \multicolumn{4}{|c|}{2001} & \multicolumn{4}{|c|}{2002} & \multicolumn{4}{|c|}{2003} & 2004 \\
\hline Quarters & 1 & 2 & 3 & 4 & 1 & 2 & 3 & 4 & 1 & 2 & 3 & 4 & $1-4$ \\
\hline Leaving quantities & 10352 & 13351 & 14693 & 14912 & 12614 & 14244 & 14409 & 15765 & 12888 & 14877 & 14040 & 17437 & 64119 \\
\hline
\end{tabular}
growth

\begin{tabular}{|c|c|c|c|c|c|c|c|c|c|c|c|c|c|c|}
\hline Years & \multicolumn{4}{|c|}{2001} & \multicolumn{4}{|c|}{2002} & \multicolumn{4}{|c|}{2003} & 2004 & 2005 \\
\hline Quarters & 1 & 2 & 3 & 4 & 1 & 2 & 3 & 4 & 1 & 2 & 3 & 4 & $1-4$ & $1-4$ \\
\hline Leaving quantities & 10352 & 13351 & 14693 & 14912 & 12614 & 14244 & 14409 & 15765 & 12888 & 14877 & 14040 & 17437 & 64119 & $\begin{array}{c}\text { Fore- } \\
\text { cast }\end{array}$ \\
\hline linear dependence, $y$ & 13422 & 13591 & 13760 & 13930 & 14099 & 14268 & 14437 & 14607 & 14776 & 14945 & 15114 & 15283 & & \\
\hline non-linear dependence, $y^{\prime \prime}$ & 13306 & 13397 & 13515 & 13658 & 13827 & 14022 & 14243 & 14490 & 14763 & 15061 & 15386 & 15736 & 71143 & 73350 \\
\hline
\end{tabular}

Table 8. Quantities of freight road vehicles leaving Lithuania through the Russian border

Table 9. Quantities of freight road vehicles leaving Lithuania through the Russian border show the tendency of growth 


\subsection{Forecast of quantity of road vehicles com- ing to Lithuania through the Russian border}

Table 10 presents statistical data on the quantities of freight road vehicles coming to Lithuania through the Russian border within the period from 2001 to 2004. By applying the methods of regressive and correlation analysis used for forecasting of transport activities we find the dependence $y=f(x)$. This dependence can be linear and non-linear.

Linear dependence: $y=a x+b$.

Non-linear dependence: $y^{\prime \prime}=a x^{2}+b x+c$.

Having performed the calculations we obtain the equation of linear dependence:

$$
y=282,40 x+12890,24 .
$$

Non-linear dependence equation:

$$
y^{\prime \prime}=15,16 x^{2}+267,24 x+12571,93 \text {. }
$$

Calculated values $y$ and $y^{\prime \prime}$ are presented in Table 11.

\section{Conclusions}

1. By applying multidimensional regression and correlation analysis for the forecasting of transport flows and after performing the calculations we obtain the equation with one unknown quantity - the time. Having this equation we will be able to forecast the changes and trends of road transport flows.

2. Queuing at the road border-crossing posts indicates the problems of Lithuanian customs operation and shows the growth of road transport flows.

3 . By applying the theory of mass attendance service of flows for the evaluation of queuing at bordercrossing areas and having defined the law, we shall be able to find the formula of probability density.

\section{References}

1. Southworth, F.; Bruce, P. Intermodal and intermodal freight network modelling. Transportation Research, Part C 8, 2000, p 147-166.

2. Coule, J.; Bordi, E.; Carinato, J. Transportations Third edition. USA, 1999. $525 \mathrm{p}$.

3. Transport of fast Changing Europe. Vers un Reseau European des systems de transport by Group Transport 2000 Plus. Brussels, 2000. 90 p.

4. Baublys, A. Introduction to the theory of transport system (Transporto sistemos teorijos ivivadas). Vilnius: Technika, 1997. 298 p (in Lithuanian).

5. Baublys, A. Assessment of statistical probability of the technological transportation process. Transport, 2002, Vol XVII, No 4, p. 127-136.

6. Baublys, A. Transport system: models of development and forecast. Monoghraph. Vilnius: Technika, 2003. $204 \mathrm{p}$.

7. Grau, B. Typical technological process of a cellarge working station (Типовой технологический процесс работы сортировочной станции). Moscow: Transport, 1995 (in Russian).

8. Sotnikov, E. Elements of managing theory by qualification system (Элементы теории управления качеством системы). Minsk: Nauka i technika, 2001 (in Russian).

9. Jarašūniene, A. The optimization of transport flows crossing Lithuanian customs-houses. Transport, 2002, Vol XVII, No 1, p. 15-18.

10. Jarašūnienè, A. Formulation of optimal international freight transport objective. Transport, 2002, Vol XVII, No 5, p. 201-204.

11. Batarlienè, N. Mathematics-statistics methods of transport tasks (Transporto uždavinių matematiniai-statistiniai metodai). Vilnius: Technika, 2003.159 p. (in Lithuanian).

12. Musteikis, M. The road traffic flow throughput problems and the ways of quickening in Lithuanian customs. Vilnius, VGTU, 2004. Final work of master studies.

\begin{tabular}{|c|c|c|c|c|c|c|c|c|c|c|c|c|c|}
\hline Years & \multicolumn{4}{|c|}{2001} & \multicolumn{4}{|c|}{2002} & \multicolumn{4}{|c|}{2003} & 2004 \\
\hline Quarters & 1 & 2 & 3 & 4 & 1 & 2 & 3 & 4 & 1 & 2 & 3 & 4 & $1-4$ \\
\hline Coming quantities & 9515 & 11979 & 13511 & 13529 & 12102 & 13425 & 13858 & 14141 & 13014 & 14771 & 13895 & 17154 & 63911 \\
\hline
\end{tabular}

Table 10. Quantities of freight road vehicles coming to Lithuania through the Russian border

Table 11. Quantities of freight road vehicles leaving Lithuania through the Russian border show the tendency of

\begin{tabular}{|c|c|c|c|c|c|c|c|c|c|c|c|c|c|c|}
\hline Years & \multicolumn{4}{|c|}{2001} & \multicolumn{4}{|c|}{2002} & \multicolumn{4}{|c|}{2003} & 2004 & 2005 \\
\hline Quarters & 1 & 2 & 3 & 4 & 1 & 2 & 3 & 4 & 1 & 2 & 3 & 4 & $1-4$ & $1-4$ \\
\hline Leaving quantities & 9515 & 11979 & 13511 & 13529 & 12102 & 13425 & 13858 & 14141 & 13014 & 14771 & 13895 & 17154 & 63911 & $\begin{array}{c}\text { Fore- } \\
\text { cast }\end{array}$ \\
\hline linear dependence, $y$ & 12043 & 12325 & 12608 & 12890 & 13173 & 13455 & 13737 & 14020 & 14302 & 14585 & 14867 & 15149 & & \\
\hline non-linear dependence, $y^{\prime \prime}$ & 11907 & 12098 & 12320 & 12572 & 12854 & 13167 & 13510 & 13883 & 14287 & 14721 & 15185 & 15680 & 65813 & 66943 \\
\hline
\end{tabular}
growth 